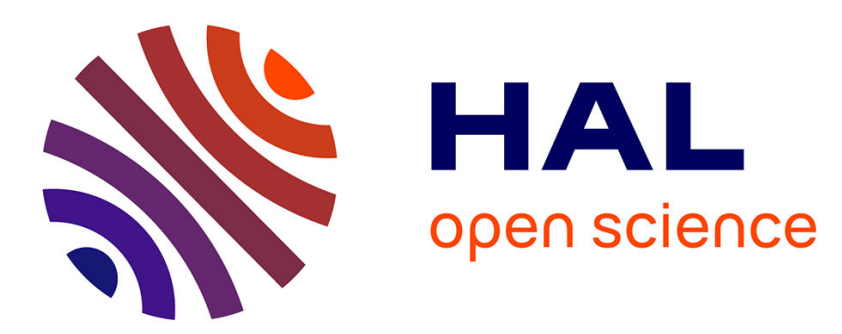

\title{
UV to NIR photon conversion in Nd-doped rutile and anatase titanium dioxide films for silicon solar cell application
}

\author{
E Le Boulbar, E Millon, E Ntsoenzok, B Hakim, W Seiler, C \\ Boulmer-Leborgne, J Perrière
}

\section{To cite this version:}

E Le Boulbar, E Millon, E Ntsoenzok, B Hakim, W Seiler, et al.. UV to NIR photon conversion in Nd-doped rutile and anatase titanium dioxide films for silicon solar cell application. Optical Materials, 2012, 34, pp.1419-1425. 10.1016/j.optmat.2012.02.033 . hal-01202536

\section{HAL Id: hal-01202536 https://hal.science/hal-01202536}

Submitted on 21 Sep 2015

HAL is a multi-disciplinary open access archive for the deposit and dissemination of scientific research documents, whether they are published or not. The documents may come from teaching and research institutions in France or abroad, or from public or private research centers.
L'archive ouverte pluridisciplinaire HAL, est destinée au dépôt et à la diffusion de documents scientifiques de niveau recherche, publiés ou non, émanant des établissements d'enseignement et de recherche français ou étrangers, des laboratoires publics ou privés. 


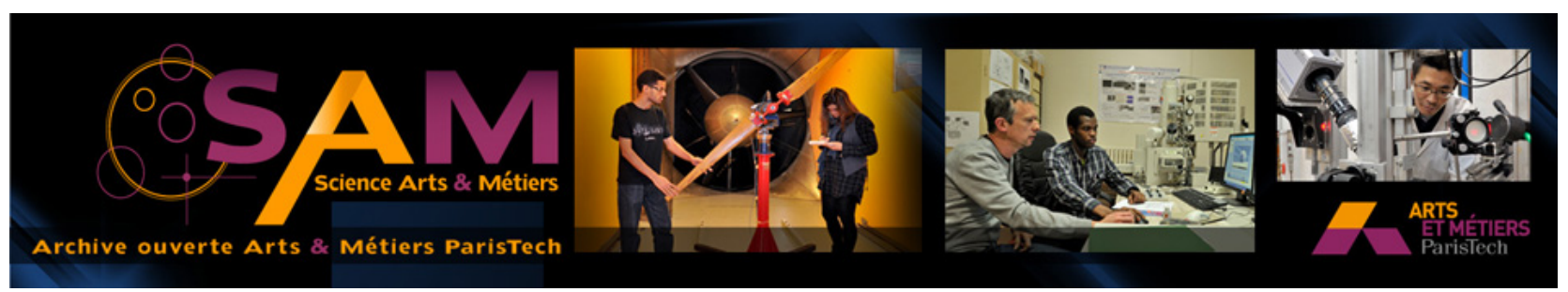

\section{Science Arts \& Métiers (SAM)}

is an open access repository that collects the work of Arts et Métiers ParisTech researchers and makes it freely available over the web where possible.

This is an author-deposited version published in: http://sam.ensam.eu

Handle ID: .http://hdl.handle.net/10985/10075

\section{To cite this version :}

E LE BOULBAR, E MILLON, E NTSOENZOK, B HAKIM, W SEILER, C BOULMER-LEBORGNE, $J$ PERRIERE - UV to NIR photon conversion in Nd-doped rutile and anatase titanium dioxide films for silicon solar cell application - Optical Materials - Vol. 34, p.1419-1425 - 2012 


\title{
UV to NIR photon conversion in Nd-doped rutile and anatase titanium dioxide films for silicon solar cell application
}

\author{
E. Le Boulbar ${ }^{\mathrm{a}, *}$, E. Millon ${ }^{\mathrm{a}}$, E. Ntsoenzok ${ }^{\mathrm{b}}$, B. Hakim ${ }^{\mathrm{b}}$, W. Seiler ${ }^{\mathrm{c}}$, C. Boulmer-Leborgne ${ }^{\mathrm{a}}$, J. Perrière ${ }^{\mathrm{d}}$ \\ ${ }^{a}$ GREMI, UMR 7344 CNRS - Université d'Orléans, BP 6744, 45067 Orléans Cedex 2, France \\ ${ }^{\mathrm{b}}$ CEMHTI, UPR 3079 CNRS, 1D avenue de la recherche scientifique, 45071 Orléans, France \\ c PIMM, UMR 8006 CNRS - ENSAM, 151 Boulevard de l'Hôpital, 75013 Paris, France \\ d INSP, UMR 7588 CNRS - Université Paris 6, 4 place Jussieu, 75005 Paris, France
}

Keywords:

Titanium dioxide

Anatase

Rutile

Neodymium

Photoluminescence

Down shifting

\begin{abstract}
A B S T R A C T
Undoped and Nd-doped titanium dioxide anatase and rutile films have been grown by pulsed-laser deposition at $700{ }^{\circ} \mathrm{C}$ under $0.1 \mathrm{mbar}_{2}$. By selecting adequate substrates, $\mathrm{TiO}_{2}$ films doped with 1,2 or 5 at.\% Nd were grown and constituted with polycrystalline rutile, highly oriented (2 00 ) rutile film, or oriented $\left(\begin{array}{lll}0 & 0 & 4\end{array}\right)$ anatase. An UV to NIR photon conversion is evidenced in the films. Indeed, intense and wellresolved emission lines from $\mathrm{Nd}^{3+}$ have been observed upon excitation above the $\mathrm{TiO}_{2}$ bandgap at room temperature. The sensitised emission of $\mathrm{Nd}^{3+}$ is found to be much efficient in rutile than in anatase structure. Low temperature photoluminescence measurements lead to fine resolved peaks corresponding to the $\mathrm{Nd}^{3+} 4 \mathrm{f}$ transitions with different spectral characteristic according to the host matrix used. Photoluminescence dependence temperature evidences that the light emission from $\mathrm{Nd}^{3+}$ in anatase-based films is probably influenced by the presence of self-trapped excitons or by orbital interaction. Mechanisms of sensitisation host to $\mathrm{Nd}^{3+}$ are proposed for both matrixes. Finally, the $\mathrm{Nd}$ dopant concentration and the microstructure of $\mathrm{TiO}_{2}$ rutile films are found to affect the photoluminescence emission intensity. Rutile film $\left(\begin{array}{lll}2 & 0 & 0\end{array}\right)$ oriented is the most adapted host matrix to sensitise 1 at.\% $\mathrm{Nd}^{3+}$ ions for an emission around $1064 \mathrm{~nm}$ making such Nd-doped layers interesting for photon conversion by down shifting process.
\end{abstract}

\section{Introduction}

The best single crystal silicon solar cell efficiency reaches a maximum of $24.7 \%$ [1] close to the limit of $31 \%$ calculated by Shockley and Queisser [2]. One of the origins of this limited efficiency is related to the spectral mismatch: photons with energy smaller than the band-gap are not absorbed (sub-band-gap transmission) and a large part of the energy of photons with energy larger than the band gap is lost as heat (thermalization losses). Photon management is one of the third generation photovoltaic principles which can lead to the improvement of silicon solar cell yield [3]. High energy photon might be split in one or two photons with a smaller energy. Each of these photons can subsequently be absorbed by the solar cell and generate an electron-hole pair. These processes, known as down-shifting (DS) for one emitted photon or down-conversion (DC) for two emitted photons, are beneficial for solar cells with a smaller band-gap where thermalization losses are the major loss factor. Lanthanides ions are fitted to DS or DC purpose as their atomic energy levels allow efficient spectral

\footnotetext{
* Corresponding author.

E-mail addresses: emmanuel.leboulbar@gmail.com, E.Le.Boulbar@bath.ac.uk (E. Le Boulbar)
}

conversion. DC of UV or visible photons into more than one NIR photons with lanthanides ions was first demonstrated in $\mathrm{Y}$, $\mathrm{YbPO}_{4}: \mathrm{Tb}^{3+}[4]$. After excitation into the ${ }^{5} \mathrm{D}_{4}$ state of the $\mathrm{Tb}^{3+}$ ion, two neighbouring $\mathrm{Yb}^{3+}$ ions are excited through a cooperative energy transfer process. The ${ }^{5} \mathrm{D}_{4}$ level of $\mathrm{Tb}^{3+}$ is about twice the energy of the $\mathrm{Yb}^{3+}{ }^{2} \mathrm{~F}_{5 / 2}$ level, and after energy transfer $\mathrm{Yb}^{3+}$ emission is observed around $1000 \mathrm{~nm}$. This emission is just above the band gap of crystalline silicon which makes $\mathrm{Yb}^{3+}$ an attractive candidate for DC materials to be used in combination with silicon solar cells. More recently, cooperative DC has also been reported for $\mathrm{Tb}^{3+} / \mathrm{Yb}^{3+}$ in other host materials and with other lanthanide couples $\mathrm{Pr}^{3+} / \mathrm{Yb}^{3+} ; \mathrm{Tm}^{3+} / \mathrm{Yb}^{3+}$ and $\mathrm{Nd}^{3+} / \mathrm{Yb}^{3+}$ [5-12]. Rare earth ion couples seems to be adequate for UV to NIR photons conversion as theoretical and experimental calculation of external quantum efficiency have reached more than $100 \%$ efficiency [9]. Nevertheless, these promising results on DC with lanthanides do not hide remaining challenge. Indeed, the absorption strength of $4 \mathrm{f}-4 \mathrm{f}$ transition is very weak and limited to narrow lines, which does not allow absorption of a large part of solar cell spectrum. To solve the absorption problem a third ion or a host matrix is required to work as a sensitizer which could absorbed efficiently all light in the UV and visible part of the spectrum up to $\sim 500 \mathrm{~nm}$ and then transfer energy to the DC couple, e.g. the ${ }^{3} \mathrm{P}_{0}$ level of $\mathrm{Pr}^{3+}[9]$. 
Richards [13] pointed out that $\mathrm{TiO}_{2}$ should be an interesting matrix to host rare earth ions because of its high-refractive index, and its excellent transparency to visible/NIR light. Besides, $\mathrm{Nd}^{3+}$ ion is of particular interest for energy transfer as it has plenty of high energy level suitable to overlap $\mathrm{TiO}_{2}$ conduction band and ${ }^{4} \mathrm{~F}_{3 / 2} \rightarrow{ }^{4} \mathrm{I}_{J}$ transitions are just above silicon energy band gap. In most reported cases, selected matrix is anatase and no work has been focused on structure and microstructure in relation with energy transfer efficiency and mechanisms. Since anatase (tetragonal, space group I4 1 amd (No. 141), lattice parameters: $a=b=0.378$ $\mathrm{nm}$ and $c=0.951 \mathrm{~nm}$ ) and rutile (tetragonal, space group $\mathrm{P} 4_{2} / \mathrm{mnm}$ (No. 136), lattice parameters: $a=b=0.459 \mathrm{~nm}$ and $c=0.296$ $\mathrm{nm}$ ) display different structural and optical properties as well as different phonon energy ( $h v_{\max }$ is 650 and $815 \mathrm{~cm}^{-1}$, respectively [14-16]) the $\mathrm{TiO}_{2}$ host matrix might affect $\mathrm{Ln}^{3+}$ luminescence and transfer properties. In the same way, the structural properties (crystallinity, grain size, crystallite orientation in films) might infer particular luminescence emission.

In this paper, the photoluminescence (PL) properties of $\mathrm{Nd}^{3+}$ have been recorded upon excitation of $\mathrm{TiO}_{2}$ band gap in order to investigate matrix to $\mathrm{Nd}$ energy transfer and the related effect of the structural properties of the $\mathrm{TiO}_{2}$ host matrix. At this aim, the crystallinity and the main axis growth of $\mathrm{TiO}_{2}$ anatase or rutile films have been controlled by using the pulsed-laser deposition (PLD) method which is well-adapted to growth high crystalline quality thin films with complex composition. Indeed, the nature of $\mathrm{TiO}_{2}$ phases and their main axis growth can be adjusted by choosing appropriate substrates as $\mathrm{LaAlO}_{3}\left(\begin{array}{lll}1 & 0 & 0\end{array}\right)$ (rhombohedral at room temperature and usually defined as hexagonal, space group R-3c (No. 167), lattice parameters: $a=0.536 \mathrm{~nm}, c=1.311$ $\mathrm{nm}$. It can also be represented as pseudocubic with $a=0.3793$ $\mathrm{nm}$ ), $\mathrm{Al}_{2} \mathrm{O}_{3}\left(\begin{array}{llll}0 & 0 & 0 & 1\end{array}\right)$ (hexagonal, space group $\mathrm{R}-3 \mathrm{c}$ (No. 167), lattice parameters: $a=0.475 \mathrm{~nm}, c=1.298 \mathrm{~nm}$.), or silicon substrate [1719]. Host-sensitised $\mathrm{TiO}_{2}: \mathrm{Nd}^{3+}$ energy transfer has been therefore recorded in both anatase (labelled $\mathrm{A}-\mathrm{TiO}_{2}$ in this paper) and rutile $\left(\mathrm{R}-\mathrm{TiO}_{2}\right)$ films with various structural properties. The $\mathrm{Nd}^{3+}$ surrounding and the energy transfer from the $\mathrm{TiO}_{2}$ matrixes to $\mathrm{Nd}^{3+}$ ions are analysed and the effects of the matrix and the $\mathrm{Nd}^{3+}$ doping content are evidenced. Finally, the integrated PL intensity recorded on $\mathrm{R}-\mathrm{TiO}_{2}$ films is discussed according to the microstructure of films (polycrystalline or oriented).

\section{Experimental section}

PLD is a method particularly adapted for the growth of complex oxide films [20,21]. $\mathrm{TiO}_{2}$ thin films doped $\mathrm{Nd}^{3+}$ were grown by PLD with a KrF Lambda Physics Compex 201 laser (248 nm, 27 ns, $20 \mathrm{~Hz}$ pulses). The experimental set-up was described elsewhere [22]. Depositions were performed on $10 \mathrm{~mm} \times 10 \mathrm{~mm} \times 0.5 \mathrm{~mm}$ single crystal $\mathrm{Al}_{2} \mathrm{O}_{3}\left(\begin{array}{llll}0 & 0 & 0 & 1\end{array}\right), \mathrm{LaAlO}_{3}\left(\begin{array}{lll}1 & 0 & 0\end{array}\right)$ or $\mathrm{Si}\left(\begin{array}{lll}1 & 0 & 0\end{array}\right)$ substrates. The laser was focused onto the target with a fluence of $4 \mathrm{~J} \mathrm{~cm}^{-2}$. The incident angle of the beam to the rotating target surface was fixed at $45^{\circ}$. Homemade one inch titanium oxide targets with $1.0,2.0$ or 5.0 at.\% Nd-doped concentration were used for the experiments. The substrate to target distance was set to $4.5 \mathrm{~cm}$ along the normal from the target. Ultra-pure oxygen was introduced into the vacuum chamber with a mass flow controller to maintain the desired partial pressure $\left(10^{-1} \mathrm{mbar}\right)$. Substrates were silver pasted onto the heater substrate holder parallel to the target. Substrates were heated to the desired growth temperature $\left(T_{\mathrm{s}}=70{ }^{\circ} \mathrm{C}\right)$ and held at growth temperature for $10 \mathrm{~min}$ both before and after the deposition.

The thickness and composition of the titanium oxide films were measured by Rutherford backscattering spectrometry (RBS), using a $2 \mathrm{MeV}$ energy ${ }^{4} \mathrm{He}^{2+}$ ion beams from the Van de Graaff accelerator of the SAFIR IBA Laboratory, Université Pierre et Marie Curie, Paris, France. The precise determination of the in-depth distribution of the elements of films and substrates was obtained by the RUMP simulation program. Such an analysis provides the titanium and oxygen concentrations in the films with a relative precision close to $4 \%$, mainly due to the low RBS yield on oxygen. Moreover, this RBS analysis demonstrates the absence of interdiffusion between the titanium oxide phases and the substrates (whatever the nature and orientation of the single crystal substrate) despite growth performed at relatively high temperature $\left(700^{\circ} \mathrm{C}\right)$. The structural characterizations of the titanium oxide films were carried out by X-ray diffraction (XRD) analyses using a four circle diffractometer (Philips Xpert MRD) with the $\mathrm{CuK} \alpha$ radiation $(\lambda=0.154 \mathrm{~nm})$. The nature of the crystalline phases, their axes parameters and their eventual preferential orientations with respect to the substrates were investigated in the symmetric Bragg-Brentano geometry.

Optical transmission measurements were performed on undoped rutile and anatase films or doped with $\mathrm{Nd}^{3+}$ at contents of

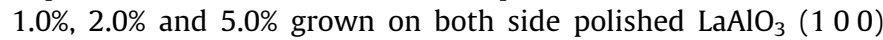
and sapphire substrates using a spectrophotometer Jasco UVVisible V-530, with a resolution of $2 \mathrm{~nm}$, in $300-1000 \mathrm{~nm}$ wavelength range. Spectrum transmission were corrected from $\mathrm{LaAlO}_{3}$ (1 00 ) and sapphire substrate absorption for all samples.

Photoluminescence emission spectra were recorded upon an UV excitation at $\lambda=364 \mathrm{~nm}$ provided by a Spectra Physics argon laser. Jobin-Yvon iHR320 spectrometer composed of a Cnerzy-Turner monochromator and an InGaAs sensor were used to record photoluminescence intensity with respect to wavelength. Spectral resolution was set to the limit of our equipment, i.e. $0.5 \mathrm{~nm}$ for each step. Photoluminescence spectra were normalised according to films thickness.

\section{Results and discussion}

\subsection{Samples composition, crystalline structure and optical properties}

The RBS experiments evidences that the films are nearly stoichiometric as an $\mathrm{O} / \mathrm{Ti}$ ratio equal to 2 is measured on the films whatever the substrate used. Such composition is classically observed on titanium oxide film grown under oxygen pressure $(0.1 \mathrm{mbar})$. According to RBS measurements, the concentration of $\mathrm{Nd}^{3+}$ in the $\mathrm{TiO}_{2}$ films reaches $1.0,2.0$ or 5.0 at.\%.

The structural properties have been investigated by XRD on undoped and Nd-doped $\mathrm{TiO}_{2}$ films on the different substrates. Fig. 1 shows the XRD patterns of undoped $\mathrm{TiO}_{2}$ films. On $\mathrm{LaAlO}_{3}\left(\begin{array}{lll}1 & 0 & 0\end{array}\right)$ substrate, the peak located at $2 \theta=37.80^{\circ}$, corresponds to a film with the anatase single phase oriented according to the $\left(\begin{array}{lll}0 & 0 & 4\end{array}\right)$ plane parallel to the surface substrate (such film is labelled $\mathrm{A}_{004}$ ). The growth of $\mathrm{TiO}_{2}$ films on both $\mathrm{Al}_{2} \mathrm{O}_{3}\left(\begin{array}{llll}0 & 0 & 0 & 1\end{array}\right)$ substrate show a main peak at $2 \theta=39.18^{\circ}$, which is related to the growth of rutile (2 00$)\left(R_{200}\right)$ oriented film, respectively. The diffraction peaks of films grown on $\mathrm{Si}\left(\begin{array}{lll}1 & 0 & 0\end{array}\right)$ substrate can be indexed as the polycrystalline rutile phase (here labelled $\mathrm{R}_{\mathrm{PC}}$ ). For $\mathrm{TiO}_{2}$ films doped by $\mathrm{Nd}^{3+}$, the XRD diagrams are very similar (the same phases and orientations are observed) and no peak related to other impurity phases such as neodymium oxides, or neodymium titanium oxides are observed. Inserted $\mathrm{Nd}$ ion into rutile and anatase matrixes does

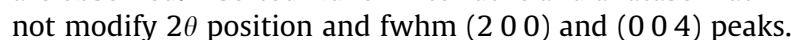

UV-Visible transmission spectra of undoped and Nd-doped $\mathrm{A}_{004}$ and $R_{200}$ thin films are shown in Fig. 2. Doping rutile and anatase do not modify the $95 \%$ and $85 \%$ visible transparency of $\mathrm{A}_{004}$ and $\mathrm{R}_{200}$ samples. The bandgap energy $\left(E_{\mathrm{g}}\right)$ of the undoped and $\mathrm{Nd}$ doped $\mathrm{A}_{004}$ and $\mathrm{R}_{200}$ films determined from the Tauc plot are listed in Table 1 . The bandgap energies of undoped $\mathrm{A}_{004}$ and $\mathrm{R}_{200}$ were determined to be $3.07 \mathrm{eV}$ and $3.17 \mathrm{eV}$, respectively. These values 


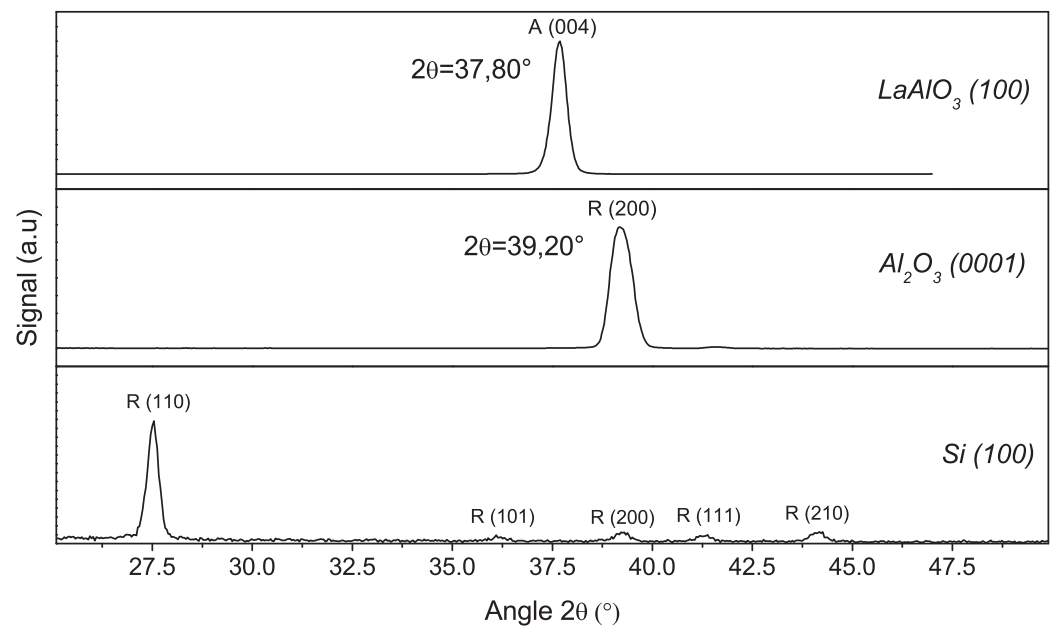

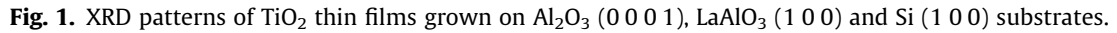

(a)

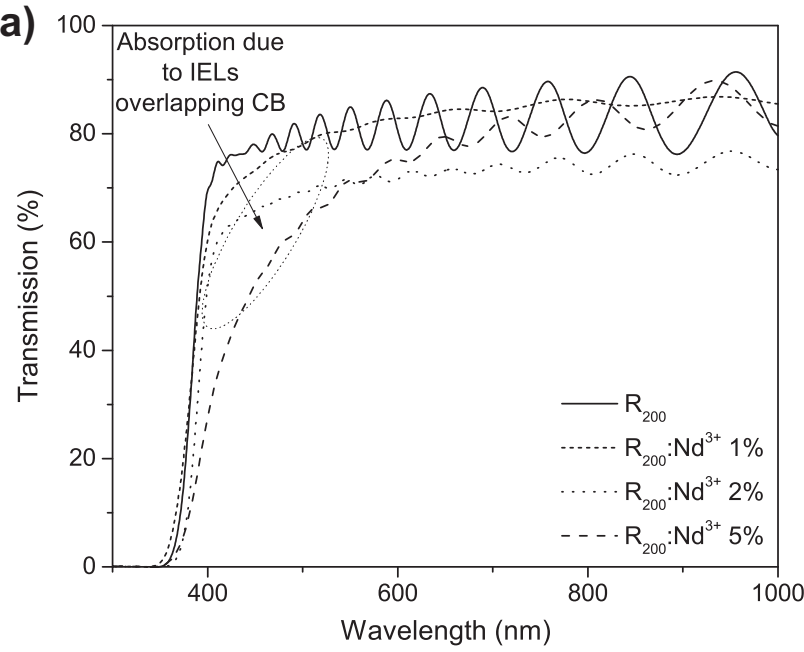

(b)

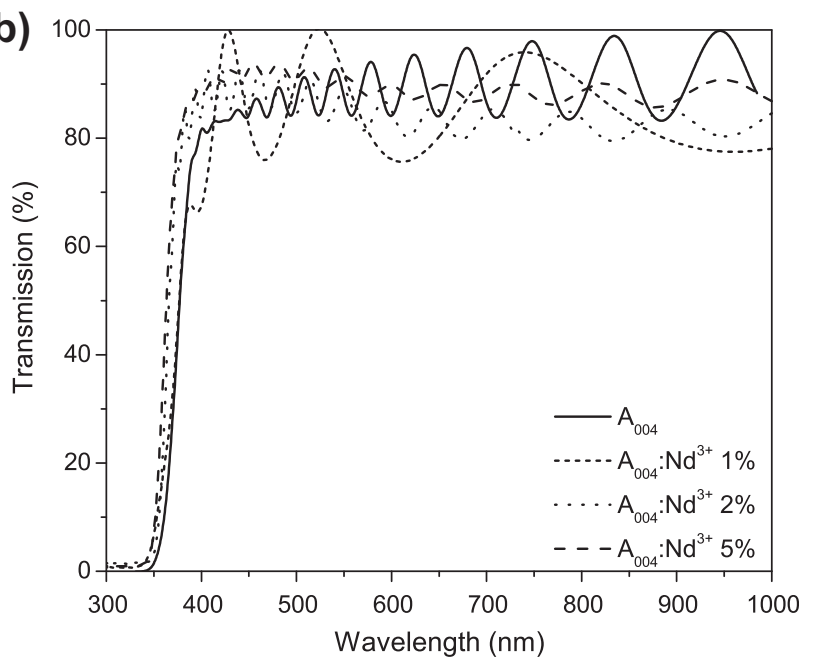

Fig. 2. Transmission spectra of: (a) $\mathrm{R}_{200}: \mathrm{Nd}^{3+}$ and (b) $\mathrm{A}_{004}: \mathrm{Nd}^{3+}$.

are lower than those of generally observed in anatase and rutile films (3.4 and $3.3 \mathrm{eV}$, respectively [23]). The optical band gap extracted by Tauc plot method shows a redshift for the $\mathrm{R}_{200}: \mathrm{Nd}^{3+}$ films from 3.07 to $2.97 \mathrm{eV}$ while the reverse effect is observed for the $\mathrm{A}_{004}: \mathrm{Nd}^{3+}$ films (blueshift, from 3.17 to $3.30 \mathrm{eV}$ ). Moreover,
Table 1

Optical band gap of $\mathrm{R}_{200}$ and $\mathrm{A}_{004}$ films doped with $0,1,2$ and 5 at.\% in $\mathrm{Nd}^{3+}$.

\begin{tabular}{lllll}
\hline $\mathrm{Nd}^{3+}$ doping (\%) & 0 & 1 & 2 & 5 \\
\hline $\mathrm{R}_{200}$ & 3.07 & 3.10 & 3.02 & 2.97 \\
$\mathrm{~A}_{004}$ & 3.17 & 3.27 & 3.28 & 3.30 \\
\hline
\end{tabular}

increasing $\mathrm{Nd}^{3+}$ content results in a biggest absorption appeared between 400 and $550 \mathrm{~nm}$ only in $\mathrm{R}_{200}$ sample (Fig. 2), and particularly for $5 \% \mathrm{R}_{200}: \mathrm{Nd}^{3+}$. This behaviour might be explained by the overlap of impurity energy levels (IELs) appearing just below the conduction band [24].

\subsection{Energy transfer in host sensitised $\mathrm{Nd}^{3+}$ doped rutile and anatase $\mathrm{TiO}_{2}$}

The PL spectra under UV excitation $(\lambda=364 \mathrm{~nm})$ of $\mathrm{R}$ - and A-TiO ${ }_{2}$ films doped with 1 at.\% $\mathrm{Nd}^{3+}$ are represented in Fig. 3. Radiative desexcitation from level ${ }^{4} \mathrm{~F}_{3 / 2}$ to ${ }^{4} \mathrm{I}_{J}(J=9 / 2,11 / 2,13 / 2)$ of $\mathrm{Nd}^{3+}$ gives rise to three groups of peaks centred at 900, 1100 and $1350 \mathrm{~nm}$ wavelengths in agreement with the emission levels involved for $\mathrm{Nd}^{3+}$ ion (Fig. 4). This emission pattern is very different from that of $\mathrm{Nd}^{3+}$ in $\mathrm{Nd}_{2} \mathrm{O}_{3}$ for both peak position and line shape,

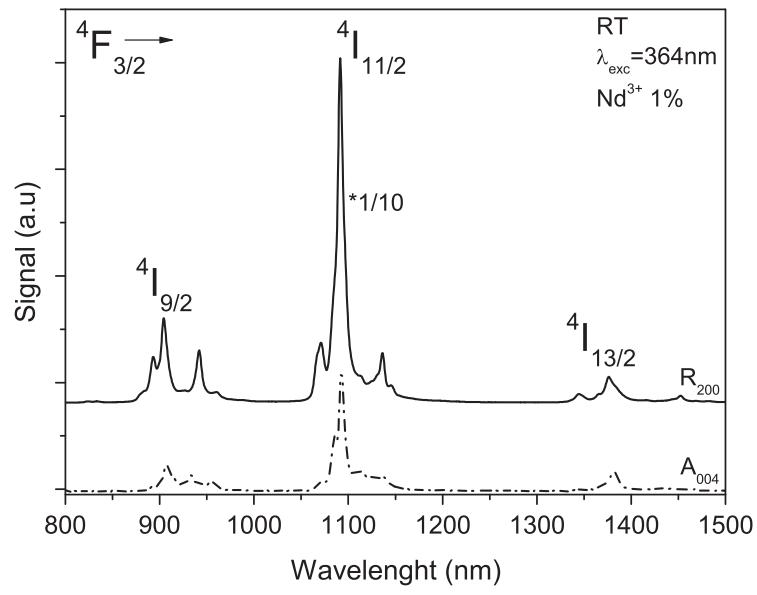

Fig. 3. Room temperature emission spectra under excitation at $364 \mathrm{~nm}$ of $1 \% \mathrm{Nd}^{3+}$ doped anatase and rutile thin films. The real intensity of PL spectrum of $\mathrm{Nd}^{3+}$-doped $R_{200}$ is 10 times greater. 


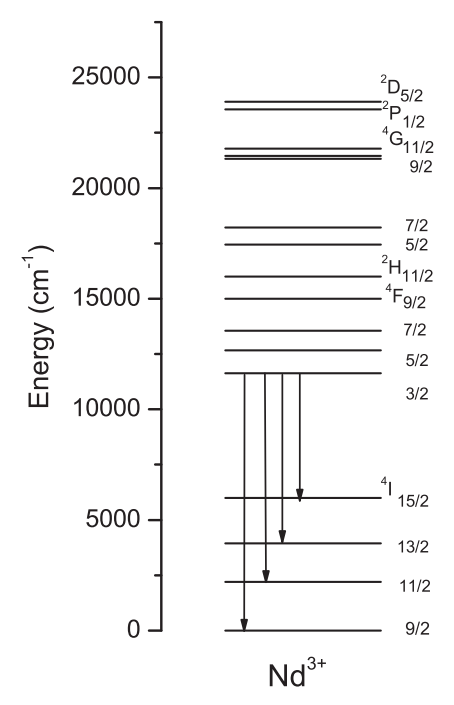

Fig. 4. Energy diagram of $\mathrm{Nd}^{3+}$ ion [26].

and thus the presence of $\mathrm{Nd}_{2} \mathrm{O}_{3}$ in the synthesised films is excluded. Low temperature PL measurements have been carried out in order to evaluate $\mathrm{Nd}^{3+}$ local environment in $\mathrm{R}^{-\mathrm{TiO}_{2}}$ (Fig. 5) and A- $\mathrm{TiO}_{2}$ (Fig. 6). A marked decrease in the width of individual crystal-field-split spectral lines appeared as the temperature is lowered. In addition, some spectral lines are absent at $10 \mathrm{~K}$ and appear only as the temperature increases (indicated by arrows in Figs. 5 and 6). As spectral lines become thinner due to the absence of thermal broadening, ${ }^{4} \mathrm{~F}_{3 / 2} \rightarrow{ }^{4} \mathrm{I}_{9 / 2},{ }^{4} \mathrm{~F}_{3 / 2} \rightarrow{ }^{4} \mathrm{I}_{11 / 2}$ and ${ }^{4} \mathrm{~F}_{3 / 2} \rightarrow{ }^{4} \mathrm{I}_{13 / 2}$ transitions in $\mathrm{Nd}^{3+}$ doped $\mathrm{R}_{200}$ and $\mathrm{A}_{004}$ can be well determined and are respectively centred at 904 (907), 1091 (1093) and 1376 (1382) $\mathrm{nm}$. Similar shifts between peak positions have been recorded [25] for $\mathrm{TiO}_{2}: \mathrm{Sm}^{3+}$ ions and has been explained by the slight difference between $\mathrm{Ln}^{3+}$ surrounding local environments. Indeed, crystal field is not equivalent in $\mathrm{TiO}_{2}$ matrixes and can be described as $\mathrm{D}_{2 \mathrm{~d}}$ symmetry of the neodymium position in anatase, whereas $D_{2 h}$ provides an accurate description for rutile environment, as shown for $\mathrm{Sm}^{3+}$
[25]. The PL measurements indicate that the neodymium position in the crystal network might also be described by lower symmetry for the $\mathrm{Nd}^{3+}$ ion in rutile.

For PL recorded at room temperature with the same experimental conditions, it is surprising to notice that $\mathrm{R}_{200}: \mathrm{Nd}^{3+}$ line spectrum is much more intense than $\mathrm{A}_{004}: \mathrm{Nd}^{3+}$ one (Fig. 3), considering anatase and rutile phonon cut-off characteristics. Note that in Fig. 3, the signal related to $\mathrm{R}_{200}: \mathrm{Nd}^{3+}$ is divided by 10 for comparison purpose. The integrated PL intensity from 800 to $1500 \mathrm{~nm}$ is 30 times larger in $\mathrm{R}_{200}: \mathrm{Nd}^{3+}$ than in $\mathrm{A}_{004}: \mathrm{Nd}^{3+}$ for $1 \% \mathrm{Nd}^{3+}$ doped samples. $\mathrm{A}$ quenching effect is highly improbable as it dominates generally at dopant concentration up to $2 \%$ [25]. This difference highlights a relevant feature in energy transfer efficiency and might be explained by different host-to- $\mathrm{Ln}^{3+}$ energy transfer pathway.

As anatase matrix has a lower cut-off phonon frequency than for rutile matrix, much intense PL spectral lines should be provided by $\mathrm{Nd}^{3+}$ ions introduced in $\mathrm{A}-\mathrm{TiO}_{2}$ rather than in $\mathrm{R}-\mathrm{TiO}_{2}$ matrix. Indeed, higher the phonon cut-off frequency is, higher the probability of non-radiative multiphonon transfer would be. The minimum number of phonon $p$ required for a transition from $4 \mathrm{f}$ state splits by an energy difference $\Delta E$ in a matrix where the phonon cut off frequency is $v_{\max }$ is given by the following equation:

$p=\frac{2 \pi \times \Delta E}{h \times v_{\max }}$

Empirically, multiphonon non-radiative transfer is a predominant process when energy is less than 5-6 cut-off phonon energy [26]. Following that empirical rule also known as gap law, a dominance of multiphonon relaxation process is predicted for all $\Delta E<3900 \mathrm{~cm}^{-1}$ and $4880 \mathrm{~cm}^{-1}$ for anatase and rutile, respectively. According to Dieke diagram [27], multiphonon process should occur for $\mathrm{Nd}^{3+}$ in anatase and rutile matrixes for all high energy states to ${ }^{4} \mathrm{~F}_{3 / 2}$ transitions but not for ${ }^{4} \mathrm{~F}_{3 / 2} \rightarrow{ }^{4} \mathrm{I}_{J}$ transitions as $\Delta E$ is bigger than $6000 \mathrm{~cm}^{-1}$.

Fig. 7 illustrates possible mechanisms for the host-to- $\mathrm{Nd}^{3+}$ sensitisation in $\mathrm{R}_{200}$ and $\mathrm{A}_{004}$ films. The excitation above the bandgap of titania films leads to the transition of electrons in $\mathrm{TiO}_{2}$ bulk from valence band (VB) to conduction band (CB) leaving holes in VB. It is believed that the energy of a recombination of electron-hole

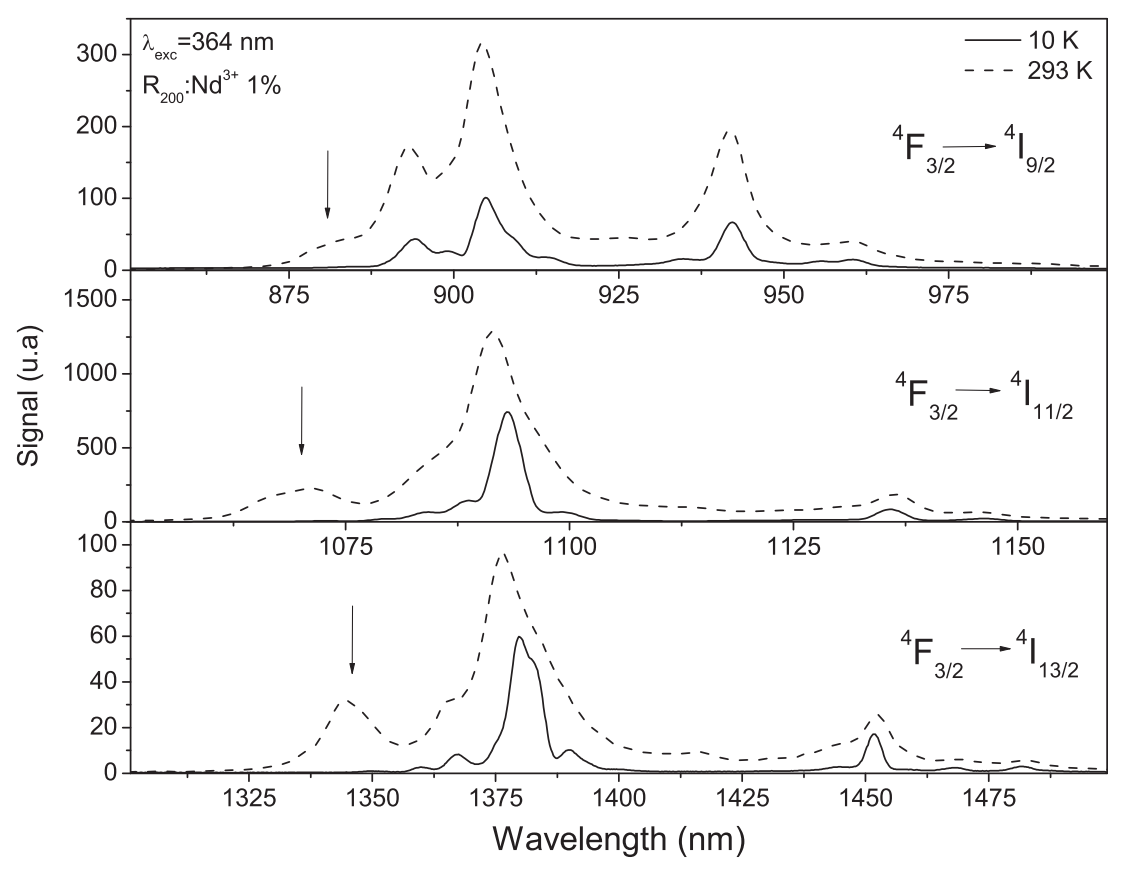

Fig. 5. $10 \mathrm{~K}$ and room temperature PL of $1 \% \mathrm{Nd}^{3+}$-doped $\mathrm{R}_{200}$ film. 


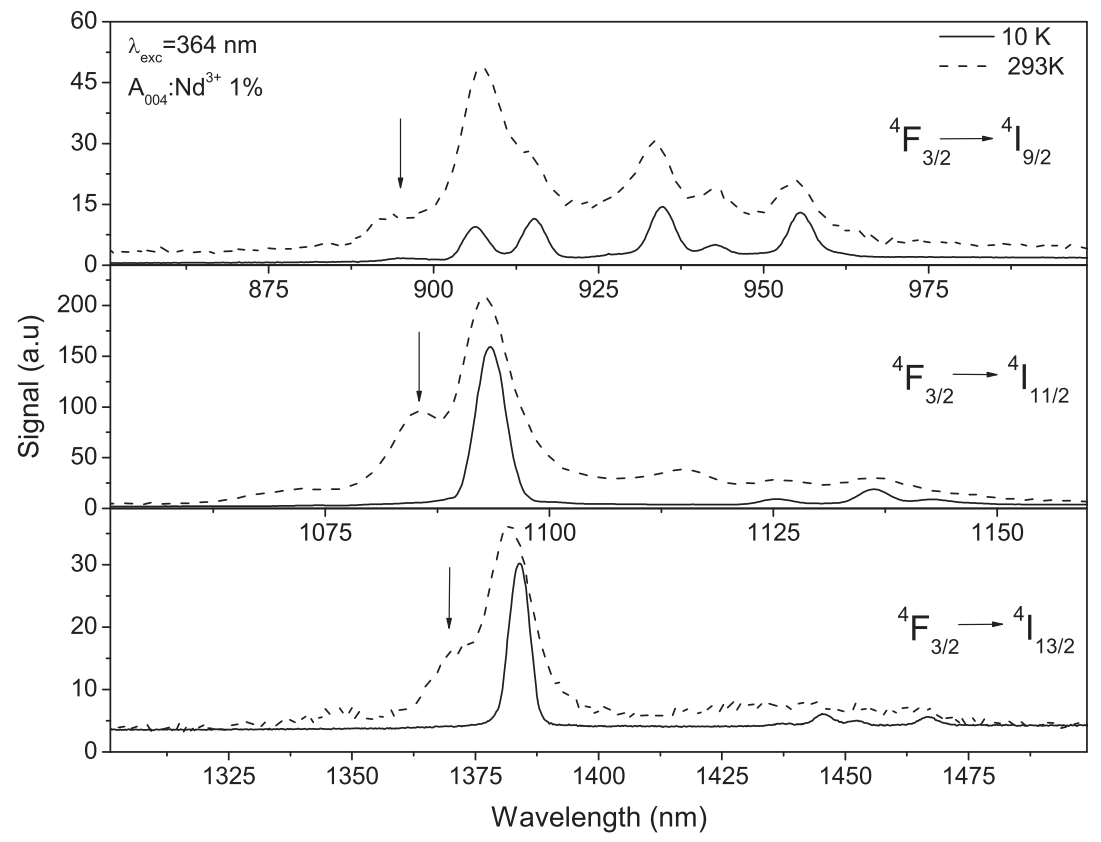

Fig. 6. $10 \mathrm{~K}$ and room temperature PL of $1 \% \mathrm{Nd}^{3+}$-doped $\mathrm{A}_{004}$ film.

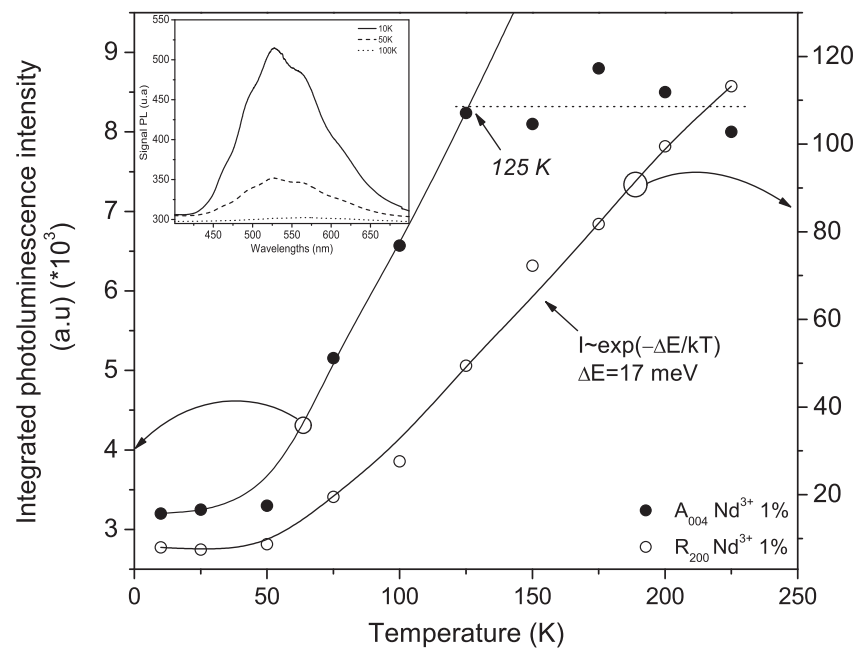

Fig. 7. Integrated PL intensity of $\mathrm{Nd}^{3+}$ signals as a function of temperature in $1 \%$ $\mathrm{Nd}^{3+}$ doped anatase and rutile films. The inset shows the self-trapped exciton luminescence peak for three temperatures: $10 \mathrm{~K}$ (full line), $50 \mathrm{~K}$ (bold dotted line), and $100 \mathrm{~K}$ (dotted line).

generated in the host can transfer non-radiatively to the excited states of $\mathrm{Nd}^{3+}$ ions for both matrixes. The first difference might be a much efficient $\mathrm{CB}$ to $\mathrm{Nd}^{3+}$ excited level in $\mathrm{R}-\mathrm{TiO}_{2}: \mathrm{Nd}^{3+}$. Indeed, as the phonon cut-off frequency is stronger in $\mathrm{R}^{-\mathrm{TiO}_{2}}$ than in A- $-\mathrm{TiO}_{2}$, the energy transfer from $\mathrm{CB}$ to $\mathrm{Nd}^{3+}$ neighbouring excited state (possibly the ${ }^{4} \mathrm{D}_{1 / 2}$ state of $\mathrm{Nd}^{3+}$ ) might be enhanced in rutile. Moreover, the efficiency of $\mathrm{CB}$ to $\mathrm{Nd}^{3+}$ energy transfer in $\mathrm{R}-\mathrm{TiO}_{2}$ might be explained by the relevant hybridizing of $\mathrm{Nd} 4 \mathrm{f}$ with $\mathrm{O}$ $2 \mathrm{p}$ orbital observed in $\mathrm{R}-\mathrm{TiO}_{2}: \mathrm{Nd}^{3+}$ which does not occurred in $\mathrm{Nd}^{3+}$-doped anatase. Indeed, it is well known that the most efficient energy transfer process involves resonance between the sensitizer and activator transition and are observed when there is an overlap of the sensitizer band and the acceptor band. Moreover, low temperature PL measurements on anatase samples showed a broad peak, that is a characteristic of self-trapped exciton (STE) defects (inset Fig. 7). Due to the presence of this defect, it may appear competitive energy transfer processes from $\mathrm{A}-\mathrm{TiO}_{2}$ $\mathrm{CB}$ to self-trapped exciton (STE) defects and $\mathrm{Nd}^{3+}$ energy states $\mathrm{A}-\mathrm{TiO}_{2}$. Indeed, overall intensity for $\mathrm{Nd}^{3+}$-doped rutile film as a function of temperature shows an exponential behaviour instead that of $\mathrm{A}_{004}: \mathrm{Nd}^{3+}$ film exhibits first an exponential behaviour until $125 \mathrm{~K}$ and then followed by a linear slope (Fig. 8). The apparition of this break can be linked to the quenching of self-trapped excitation, seen in Fig. 7 and reported in the literature at $180 \mathrm{~K}$ [28]. Such host sensitisation may be ascribed to a phonon-assisted energy transfer process since relatively weak host-to- $\operatorname{Ln}^{3+}$ sensitisation were observed at $10 \mathrm{~K}$ and as the signal is improved when the temperature increases. After the energy transfer from $\mathrm{CB}$ to $\mathrm{Nd}^{3+}$ excited state, non-radiative relaxation to ${ }^{4} \mathrm{~F}_{3 / 2}$ of $\mathrm{Nd}^{3+}$ occurs thanks to multiphonon relaxation, then ${ }^{4} \mathrm{~F}_{3 / 2} \rightarrow{ }^{4} \mathrm{I}_{J}$ producing near-infrared emissions (Fig. 8).

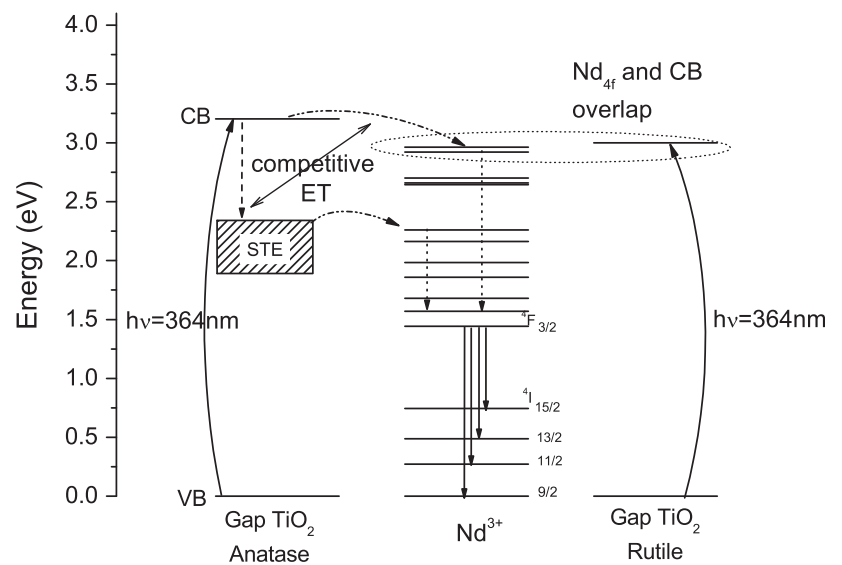

Fig. 8. Energy transfer mechanism describing competitive transfer and $\mathrm{Nd}^{3+}$ sensitisation in $\mathrm{A}-\mathrm{TiO}_{2}$ and $\mathrm{R}-\mathrm{TiO}_{2}$. One UV-blue photon absorbed by a $\mathrm{Nd}^{3+}$ ion is converted to one $\mathrm{Nd}^{3+} \mathrm{NIR}$ photons through a two-step sequential energy transfer. Solid, curved dotted, and straight arrows represent optical transition, non-radiative energy transfer, and non-radiative relaxation. 


\subsection{Effect of dopant concentration on integrated photoluminescence intensity}

Room temperature integrated PL intensities of $1 \%, 2 \%$ and $5 \%$ $\mathrm{Nd}^{3+}$-doped $\mathrm{TiO}_{2}$ films have been calculated in order to investigate the influence of the dopant concentration. As shown in Fig. 9a, an increase of $\mathrm{Nd}^{3+}$ concentration from 1 to 5 at.\% leads to increase gradually the total PL intensity for both structures. Normalised integrated signal gives rise to information about quenching, showing that $\mathrm{Nd}^{3+}$ ion luminescence efficiency is decreased by increasing dopant content (Fig. 9b). Normalised overall intensity of $\mathrm{R}_{200}: \mathrm{Nd}^{3+}$ by the doping content gives an access to emission efficiency of each $\mathrm{Ln}^{3+}$ ions. The signal corresponding to 2 or 5 at.\% $\mathrm{Nd}$ is divided by two and three referring to the lowest doping content (1\%) which means that the decrease of efficiency can be assigned to a quenching effect. Indeed, the cross-relaxation rate critically depends on the distance between the $\mathrm{Ln}^{3+}$ pairs (i.e., $\mathrm{Ln}^{3+}$ concentrations). For $\mathrm{Nd}^{3+}$ ions, it exists the following cross-relaxation dipolar transition: the energy produced by the ${ }^{4} \mathrm{~F}_{3 / 2} \rightarrow{ }^{4} \mathrm{I}_{15 / 2}$ transition of one $\mathrm{Nd}^{3+}$ ion can be resonantly transferred to another neighbouring $\mathrm{Nd}^{3+}$ ion causing the ${ }^{4} \mathrm{I}_{9 / 2} \rightarrow{ }^{4} \mathrm{I}_{15 / 2}$ excitation. The electrons in the ${ }^{4} \mathrm{I}_{15 / 2}$ excited state are nonradiatively relaxed to the ${ }^{4} I_{9 / 2}$ fundamental state. It has been observed in anatase nanocrystal, that cross relaxation occurs at
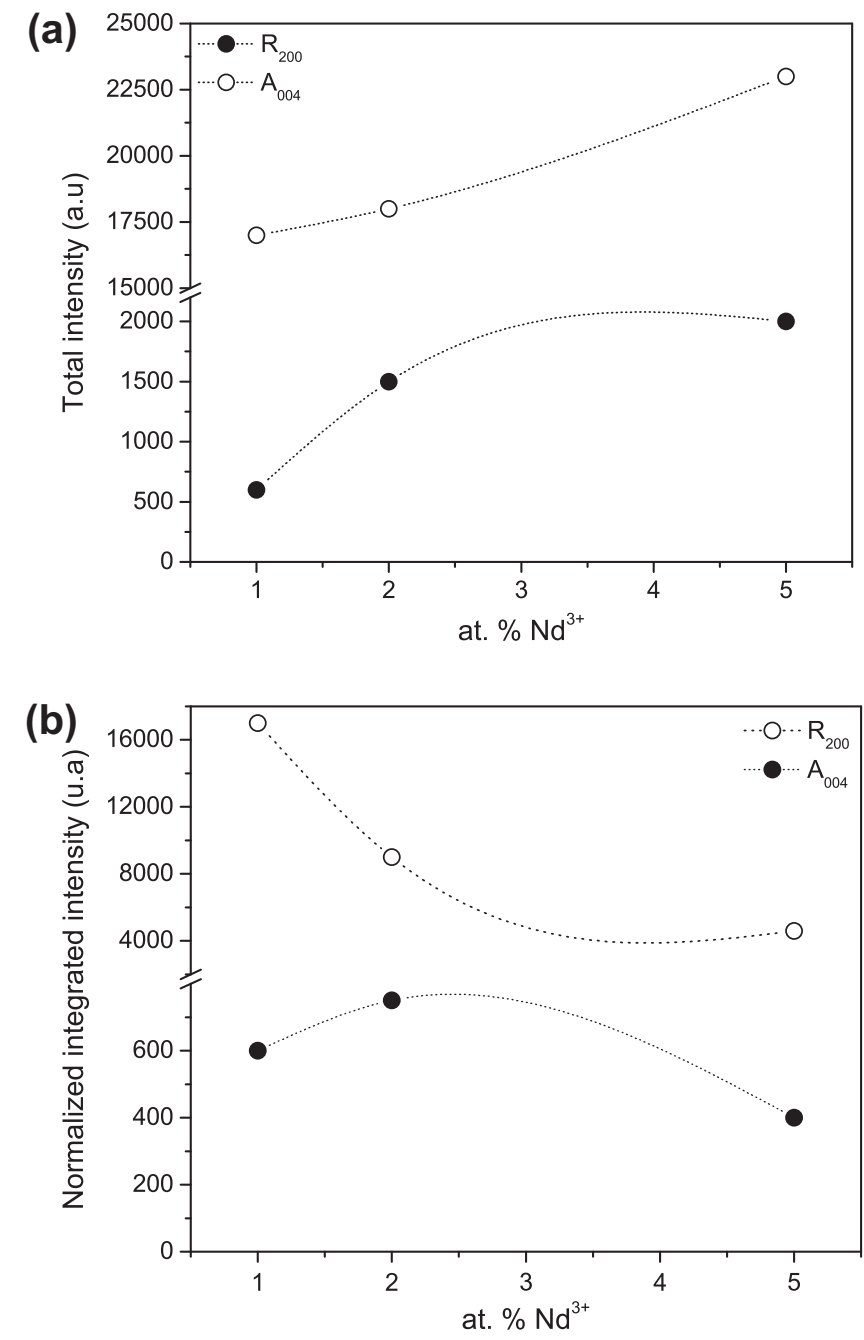

Fig. 9. Integrated (a) and normalised (b) PL intensity in the $800-1500 \mathrm{~nm}$ range corresponding to the ${ }^{4} \mathrm{~F}_{3 / 2} \rightarrow{ }^{4} \mathrm{I}_{J} \mathrm{Nd}^{3+}$ transition for $1 \%, 2 \%$ and $5 \% \mathrm{Nd}^{3+}$-doped $\mathrm{A}_{004}$ and $\mathrm{R}_{200}$ films.

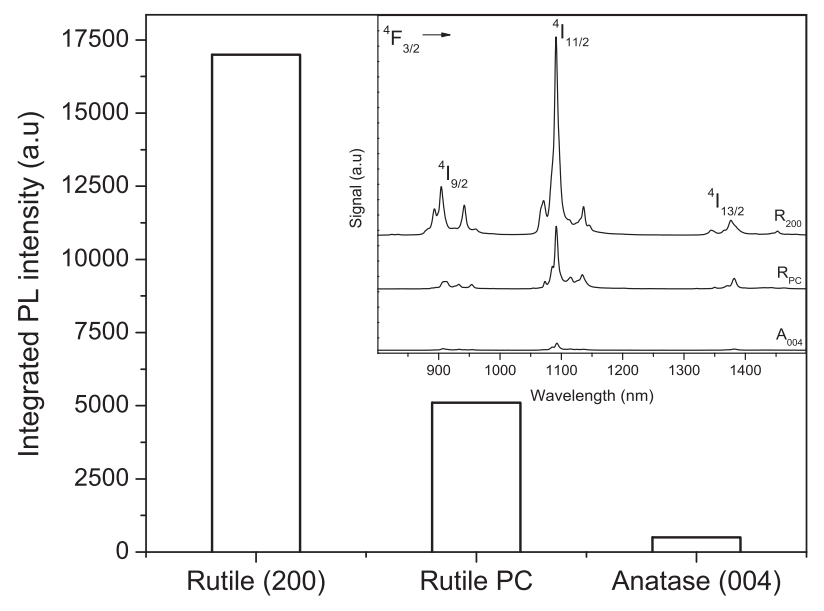

Fig. 10. UV excited room temperature integrated luminescence of $1 \% \mathrm{Nd}^{3+}$ doped $\mathrm{R}_{200}$, Rpc and $\mathrm{A}_{004}$ samples. Characteristics $\mathrm{Nd}^{3+4} \mathrm{~F}_{3 / 2}{ }^{4} \mathrm{I}_{J}$ transitions obtained in each $\mathrm{TiO}_{2}$ film are represented in insert.

Table 2

Full width half maximum of $\mathrm{TiO}_{2}$ films and relative grain size diameter calculated by the Scherrer equation.

\begin{tabular}{|c|c|c|c|c|}
\hline Films & $2 \theta\left(^{\circ}\right)$ & Phase & FWHM $\left({ }^{\circ}\right)$ & $D_{\text {Scherrer }}(\mathrm{nm})$ \\
\hline $\mathrm{R}_{200}$ & 39.20 & $\mathrm{R}-\mathrm{TiO}_{2}\left(\begin{array}{lll}2 & 0 & 0\end{array}\right)$ & 0.33 & 26 \\
\hline $\mathrm{A}_{004}$ & 37.80 & $\mathrm{~A}-\mathrm{TiO}_{2}\left(\begin{array}{lll}0 & 0 & 4\end{array}\right)$ & 0.43 & 20 \\
\hline $\mathrm{R}_{\mathrm{PC}}$ & 27.50 & $\mathrm{R}-\mathrm{TiO}_{2}(\mathrm{PC})$ & 0.32 & 28 \\
\hline
\end{tabular}

all dopant concentration and the PL signal is quenched dramatically when the amount of $\mathrm{Nd}^{3+}$ dopant was increased up to 2\% [5]. These drops are attributed to the enhancement of cross relaxation process due to higher concentration. It has to be noticed that the luminescence efficiency of $\mathrm{Nd}^{3+}$ ion decreases for higher $\mathrm{Nd}$ concentration, but the extinction of luminescence is not observed.

\subsection{Effect of rutile microstructure on integrated photoluminescence intensity}

Fig. 10 shows the integrated emission intensities from 800 to $1500 \mathrm{~nm}$ of $\mathrm{R}_{200}, \mathrm{R}_{\mathrm{PC}}$ and $\mathrm{A}_{004}$ films doped by 1 at.\% $\mathrm{Nd}^{3+} . \mathrm{A}_{004}$ has the smallest amount of integrated luminescence making anatase a non-suitable host-matrix for $\mathrm{Nd}^{3+}$ ions. The effect of rutile microstructure is investigated by taking into account XRD peaks, as it is related to the grain size of crystallites and localised strains inside the films (Table 2). It is interesting to notice that $R_{200}$ shows twice larger integrated PL signal than $\mathrm{R}_{\mathrm{PC}}$ films. Regarding XRD patterns, these differences could be explained by a better crystalline quality in $R_{200}$ rather than in $R_{P C}$ as the FWHM of ( $\left.\begin{array}{lll}2 & 0 & 0\end{array}\right)$ peak of $\mathrm{R}-\mathrm{TiO}_{2}$ is smaller than the other ones. In previous works $[17,18]$, it has been demonstrated that $\mathrm{R}-$ or $\mathrm{A}-\mathrm{TiO}_{2}$ films grown on sapphire and $\mathrm{LaAlO}_{3}$ substrates are strongly oriented according to the same out-of plane relationships evidenced in the present study and they are also epitaxied allowing for such films to be almost considered as like-single crystal. Despite its interesting structural properties, the $\mathrm{A}-\mathrm{TiO}_{2}$ films do not lead to intense PL emission due to the STE process. Consequently, the $R_{200}$ film displays the best structural properties in terms of grain size, density, and quality of film/substrate interface. The PL properties of this film are therefore more efficient than those of induced from a polycrystalline rutile film which is characterised by a higher structural disorder. 


\section{Conclusion}

Undoped and Nd-doped rutile and anatase $\mathrm{TiO}_{2}$ thin films have been successfully grown by pulsed laser deposition under $10^{-1}$ mbar at $700^{\circ} \mathrm{C}$. The nature of phase (A or R) and its main axis growth may be controlled thanks to the substrate used. Different $\mathrm{Nd}^{3+}$ doping contents have been obtained: 1, 2 and 5 at.\%. The photoluminescence of the obtained UV host-sensitised $\mathrm{Nd}^{3+}$ has been realised upon excitation of the rutile and anatase matrix. A slight difference is observed in the fine structure of the PL spectrum shape between $\mathrm{A}-\mathrm{TiO}_{2}$ and $\mathrm{R}-\mathrm{TiO}_{2}$ oriented with the $\left(\begin{array}{lll}0 & 0 & 4\end{array}\right)$ and (2 000 ) planes parallel to surface substrate, respectively. That suggests different $\mathrm{Nd}^{3+}$ local environment in the host crystal field. These differences, highlighted by the modification of rutile absorption spectrum, would induce that interactions between $\mathrm{Nd}^{3+}$ ions and $\mathrm{TiO}_{2}$ network are stronger in the rutile phase. The hostsensitisation may occur according to a phonon assisted energy transfer as the PL peak intensities in the two matrixes are growing up with respect to temperature. Nevertheless, energy transfer is found to be different in both matrixes: the transfer from rutile to $\mathrm{Nd}^{3+}$ ions is much efficient, probably both due to the $\mathrm{O} 2 \mathrm{p}$ and $\mathrm{Nd}^{3+}$ 4f hybridization while a competitive transfer involving selftrapped excitons occurs in anatase. Finally, we demonstrate that UV to NIR conversion is achieved in both anatase and rutile phase and that high crystalline quality rutile film is the most efficient matrix to host $\mathrm{Nd}^{3+}$ ions leading to the most efficient PL emission. Such $\mathrm{Nd}^{3+}$-doped rutile films are now studied as potential upper layer on silicon solar cell toward a possible improvement of the photon conversion efficiency based on a UV to NIR down shifting process.

\section{Acknowledgments}

This work was financed from the sources granted by Région Centre and ST Microelectronics. The authors would like to thank Nadia Sbai, from Institut PRISME, Université d'Orléans Chartres, France for the UV-Visible measurements. The authors are grateful to the cooperative structure around SAFIR (Université Pierre et
Marie Curie - Paris 6) for the RBS measurements. One of the authors (J. Perrière) would thank the financial support of the "Foundazione Caritro" (Trento) in the frame of the Oxi-Solar Project.

\section{References}

[1] J. Zhao, A. Wanh, M.A. Green, Prog. Photovolt.: Res. Appl. 7 (6) (1999) 471-474.

[2] W. Shockley, H.J. Queisser, J. Appl. Phys. 32 (3) (1961) 510-519.

[3] G. Conibeer, Mater. Today 10 (11) (2007) 42-50.

[4] P. Vergeer, T.J.H. Vlugt, M.H.F. Kox, M.I. den Hertog, J.P.J.M. van der Eerden, A. Meijerink, Phys. Rev. B 71 (2005) 014119.

[5] G. Lakshminarayana, Y. Hucheng, Y. Song, L. Yin, Q. Jianrong, J. Phys. D: Appl. Phys. 41 (2008) 175111.

[6] G. Lakshminarayana, J. Qiu, J. Alloys Compd. 481 (2009) 582-589.

[7] L. Aarts, B.M. van der Ende, A. Meijerink, J. Appl. Phys. 106 (2009) 023522-6.

[8] J.-M. Meijer, L. Aarts, B.M. van der Ende, T.J.H. Vlugt, A. Meijerink, Phys. Rev. B 81 (2010) 035107.

[9] B.M. Van der Ende, L. Aarts, A. Meijerink, Phys. Chem. Chem. Phys. 11 (2009) 11081-11095.

[10] H. Lin, D. Chen, Y. Yu, Z. Shan, P. Huang, A. Yang, Y. Wang, J. Alloys Compd. 509 (2011) 3363-3366.

[11] Q.Y. Zhang, C.H. Yang, Z.H. Jiang, X.H. Ji, Appl. Phys. Lett. 90 (2007) 061914-3.

[12] Q.Y. Zhang, G.F. Yang, Z.H. Jiang, Appl. Phys. Lett. 91 (2007) 051903.

[13] B.S. Richards, Solar Energy Mater. Solar Cells 90 (2006) 1189-1207.

[14] F. Jing, S. Harako, S. Komuro, X. Zhao, J. Phys. D: Appl. Phys. 42 (2009) 085109.

[15] S.P.S. Porto, P.A. Fleury, T.C. Damen, Phys. Rev. 154 (1967) 522.

[16] M. Montagna, E. Moser, F. Visintainer, M. Ferrari, L. Zampedri, A. Martucci, M. Guglielmi, M. Ivanda, J. Sol-Gel Sci. Technol. 26 (2003) 241-244.

[17] N. Sbaï, J. Perrière, W. Seiler, E. Millon, Surf. Sci. 601 (2007) 5649-5658.

[18] N. Sbaï, J. Perrière, B. Gallas, E. Millon, W. Seiler, M.C. Bernard, J. Appl. Phys. 104 (2008).

[19] S. Yamamoto, T. Sumita, Sugiharuto, A. Miyashita, H. Naramoto, Thin Solid Films 401 (2001) 88-93.

[20] A. Roemer, E. Millon, B. Vincent, A. Boudrioua, O. Pons-Y-Moll, R.M. Defourneau, W. Seiler, J. Appl. Phys. 95 (2004) 3041-3047.

[21] P.A. Atanasov, R.I. Tomov, J. Perrière, R.W. Eason, N. Vainos, R. Kliny, A. Zherikhin, E. Millon, Appl. Phys. Lett. 76 (2000) 2490-2492.

[22] E. Le Boulbar, E. Millon, J. Mathias, C. Boulmer-Leborgne, M. Nistor, F. Gherendi, N. Sbaï, J.B. Quoirin, Appl. Surf. Sci. 257 (2011) 5380-5383.

[23] H. Gudel, M. Pollnau, J. Alloys Compd. 303-304 (2000) 5317-5323.

[24] Z. Zhao, Q. Liu, J. Phys. D: Appl. Phys. 41 (2008) 085417.

[25] W.Q. Luo, R.F. Li, X.Y. Chen, J. Phys. Chem. C 113 (2009) 8772-8777.

[26] J.M. Van Dijk, M.F.H. Schuurmans, J. Chem. Phys. 78 (1983) 5317-5323.

[27] R.T. Wegh, A. Meijerink, R.J. Lamminmaki, J. Holsa, J. Lumin. 87-89 (2000) 1002-1004.

[28] V. Melnyk, V. Shymanovska, G. Puchkovska, T. Bezrodna, G. Klishevich, J. Mol. Struct. 573 (2005) 744-747. 